\title{
Economic value of disability-adjusted life years lost to violence: estimates for WHO Member States
}

\author{
David W. Brown ${ }^{1}$
}

Suggested citation

Brown DW. Economic value of disability-adjusted life years lost to violence: estimates for WHO Member States. Rev Panam Salud Publica. 2008;24(3):203-9.

\begin{abstract}
Violence is an important public health challenge with substantial economic consequences for the affected individuals, families, and communities. Using data from the World Health Organization (WHO) and the World Bank, the economic value of disability-adjusted life years (DALYs) lost due to violence in 2002 was estimated for WHO Member States and presented as a percentage of gross domestic product (GDP). Results indicated an estimated 48.4 million $D A L Y s$ were lost as a result of 1.6 million deaths due to violence in 2002, for a total estimated economic value of US\$ 151 billion (in constant US\$ for the year 2000). Expressed as a percentage of GDP, the economic value of DALYs lost due to violence ranged from $0.04 \%$ to $5.1 \%$ across the 193 Member States. Much more is needed in terms of quantifying the economic burden of violence globally, particularly in low-and middle-income countries, where the burden of violence is greatest.
\end{abstract}

Key words Violence, cost of illness.

In 2002, an estimated 1.6 million people worldwide died as a result of selfinflicted, interpersonal, or collective violence. This is roughly half the number of deaths due to HIV/AIDS, nearly equal to the number of deaths due to tuberculosis, somewhat greater than the number of deaths due to malaria, and 1.5 times the number of road traffic deaths. Of the total 1.6 million victims of violence, nearly a third (560000) were homicides, a further 870000 people killed themselves and an estimated

\footnotetext{
Send correspondence and reprint requests to: David W. Brown, P.O. Box 2572, Decatur, GA 30031, United States of America; e-mail: dwbrown. 6@gmail.com
}

170000 died as a direct result of collective violence. In addition to the high annual death toll, each year millions of people suffer non-fatal health consequences of violence (i.e., injury and disability, mental health and other behavioral disorders, and poor reproductive health) many of which can have longlasting implications.

Violence results in substantial economic costs to the individuals involved, their households, and the community as a whole. The effects of violence place an enormous burden on national economies through increased health-care and legal costs, absenteeism from work, and lost productivity. Losing a breadwinner to violence- related injuries or death often tips families into poverty or pushes poorer families further into poverty. The implications of this sudden catastrophic change for security of individuals and households are both immediate and obvious.

Thus, similar to communicable and noncommunicable diseases, violence has adverse implications for individual economic well-being. In the 2001 report, Macroeconomics and health: investing in health for economic development, the Commission on Macroeconomics and Health (the Commission) noted the high economic costs of avoidable disease totaling hundreds of billions of U.S. dollars and pointed to 
reductions in annual incomes of society, in lifetime incomes of individuals and future growth potential, particularly in the poorest countries (1). The Commission further noted the gains in economic well-being and growth to be had by preventing premature death from avoidable disease and highlighted the importance of converting disease-induced losses into dollar terms in order to assess the economic benefits that would be observed in the absence of disease (1).

With this in mind, data from the World Health Organization (WHO) and the World Bank was used to compute and estimated economic value of disability-adjusted life years (DALYs) lost due to violence for all $193 \mathrm{WHO}$ Member States. ${ }^{2}$

In their report, the Commission presented a method of converting disease-induced losses of well-being into economic terms by multiplying the annual number of lost life years due to disease by a multiple of per capita income (1). The same process was followed in this report to compute an estimate of the economic value of DALYs lost due to violence for all WHO Member States.

First, DALY data were obtained from the WHO Global Burden of Disease Estimates for 2002 for each of the WHO Member States. DALYs for a disease are the sum of the years of life lost due to premature mortality (YLL) in the population and the years lost due to disability (YLD) for incident cases of the health condition. The DALY is a health gap measure that extends the concept of potential years of life lost due to premature death to include equivalent years of "healthy" life lost in states of less than full health, broadly termed "disability" (2). One DALY represents the loss of one year of equivalent full health. These data are readily accessible from WHO (2). A detailed discussion of the data

\footnotetext{
2 Due to inadequate data availability, estimates were not computed for Barbados, Cuba, Afghanistan, Iraq, Qatar, Somalia, Andorra, Monaco, San Marino, Turkmenistan, Democratic People's Republic of Korea, Myanmar, Cook Islands, Nauru, Niue, Palau, Tokelau, or Tuvalu.
}

TABLE 1. Deaths due to violence, estimated number of disability-adjusted life years (DALYs) lost to violence, and estimated economic value ${ }^{\mathrm{a}}$ of DALYs lost to violence by WHO Region, 2002

\begin{tabular}{lcccccc}
\hline \multicolumn{1}{c}{ WHO Region } & $\begin{array}{c}\text { Deaths due to } \\
\text { violence } \\
\text { (in millions) }\end{array}$ & $\begin{array}{c}\text { Estimated number } \\
\text { of DALYs lost } \\
\text { to violence } \\
\text { (in millions) }\end{array}$ & $\begin{array}{c}\text { Estimated economic } \\
\text { value of DALYs lost } \\
\text { to violence } \\
\text { (in billions of US\$) }\end{array}$ \\
\hline African Region & 0.253 & $(16 \%)$ & 9.259 & $(19 \%)$ & 5.600 & $(4 \%)$ \\
Region of the Americas & 0.219 & $(14 \%)$ & 8.440 & $(17 \%)$ & 68.360 & $(45 \%)$ \\
Eastern Mediterranean Region & 0.098 & $(6 \%)$ & 3.189 & $(7 \%)$ & 3.002 & $(2 \%)$ \\
European Region & 0.257 & $(16 \%)$ & 6.462 & $(13 \%)$ & 33.207 & $(22 \%)$ \\
South-East Asia Region & 0.386 & $(24 \%)$ & 11.809 & $(24 \%)$ & 6.604 & $(4 \%)$ \\
Western Pacific Region & 0.402 & $(25 \%)$ & 9.270 & $(19 \%)$ & 34.297 & $(23 \%)$ \\
All regions & 1.615 & $(100 \%)$ & 48.429 & $(100 \%)$ & 151.070 & $(100 \%)$ \\
\hline
\end{tabular}

Source: Author calculations, based on references 2 and 4. a In constant US\$ for the year 2000.

sources and methods of the 2002 Global Burden of Disease Project is available in WHO's Global Programme on Evidence for Health Policy Discussion Paper No. 54 (3).

Data on 2002 gross domestic product (GDP) and 2002 GDP per capita ${ }^{3}$ for each of the WHO Member States were obtained from the World Bank (4).

After merging the two data sources into a single database by Member State, the value of DALYs lost due to violence was calculated by multiplying the estimated DALYs in 2002 for violence by the 2002 GDP per capita for each Member State. In addition, the value of DALYs lost as a percentage of total GDP in 2002 was calculated for each country.

For example, in Brazil, the estimated DALYs lost to violence during 2002 totaled 2.861 million. GDP per capita for Brazil during 2002 was US\$ 3473. The value of DALYs lost due to violence was calculated as the product of these two estimates, or approximately US\$ 9.935 billion. ${ }^{4}$

Results indicated an estimated 48.4 million DALYs were lost as a result of 1.6 million deaths due to violence in 2002 (Table 1). The estimated number of DALYs lost due to interpersonal violence was 21.3 million and that for self-directed violence was 20.7 million.

\footnotetext{
3 In constant US\$ for the year 2000.

Estimates may vary due to rounding.
}

The WHO South-East Asia Region accounted for the largest fraction of DALYs lost to violence, followed closely by the WHO African Region and the WHO Western Pacific Region (Table 1).

The estimated economic value of DALYs (in constant US $\$$ for the year 2000) lost to violence in 2002 totaled US\$ 151 billion (US\$ 58 billion, interpersonal violence; US\$ 88 billion, selfdirected violence, with the largest amount of losses occurring in the WHO Region of the Americas, followed by the WHO Western Pacific Region and the WHO European Region (Table 1).

Table 2 displays 25 countries with the largest estimated number of DALYs lost due to violence and the estimated economic value of those DALYs. Countries at the top of the list include India, China, the Russian Federation, Brazil, and the Democratic Republic of the Congo. It should be noted that while each of these countries shares a significant burden of violence problem, the aggregates can be quite different across countries. For instance, in India, the burden of violence is dominated by deaths due to selfinflicted violence (i.e., suicide) (more than 182000 suicides in 2002, and 57000 homicides). In China, more than 272000 persons died due to selfinflicted violence and nearly 39000 died as the result of homicide. In Brazil, homicide was one of the greater 
TABLE 2. Twenty-five countries with greatest number of disability-adjusted life years (DALYs) lost to violence and estimated economic value ${ }^{\mathrm{a}}$ of DALYs lost to violence in 2002

\begin{tabular}{|c|c|c|}
\hline Country & $\begin{array}{l}\text { Estimated number of } \\
\text { DALYs lost to } \\
\text { violence in } 2002 \\
\text { (in millions) }\end{array}$ & $\begin{array}{c}\text { Estimated economic } \\
\text { value of DALYs lost } \\
\text { (in billions of US\$a) } \\
\text { (rank) }\end{array}$ \\
\hline 1. India & 7.598 & $3.640(9)$ \\
\hline 2. China & 7.090 & $7.841(4)$ \\
\hline 3. Russian Federation & 3.331 & $6.556(5)$ \\
\hline 4. Brazil & 2.861 & $9.935(3)$ \\
\hline 5. Democratic Republic of the Congo & 2.004 & $0.166(58)$ \\
\hline 6. Colombia & 1.882 & $3.748(8)$ \\
\hline 7. Indonesia & 1.680 & $1.418(18)$ \\
\hline 8. Nigeria & 1.431 & $0.560(33)$ \\
\hline 9. United States of America & 1.230 & $42.646(1)$ \\
\hline 10. Sudan & 1.060 & $0.432(41)$ \\
\hline 11. Bangladesh & 0.925 & $0.357(45)$ \\
\hline 12. Pakistan & 0.833 & $0.443(39)$ \\
\hline 13. South Africa & 0.804 & $2.511(13)$ \\
\hline 14. Philippines & 0.668 & $0.680(31)$ \\
\hline 15. Ethiopia & 0.610 & $0.077(80)$ \\
\hline 16. Ukraine & 0.598 & $0.445(38)$ \\
\hline 17. Mexico & 0.596 & $3.487(10)$ \\
\hline 18. Japan & 0.569 & $20.866(2)$ \\
\hline 19. Myanmar & 0.529 & $N A^{b}$ \\
\hline 20. Venezuela & 0.484 & $2.119(15)$ \\
\hline 21. Uganda & 0.445 & $0.114(68)$ \\
\hline 22. Thailand & 0.431 & $0.908(22)$ \\
\hline 23. Somalia & 0.419 & NA \\
\hline 24. Algeria & 0.376 & $0.706(30)$ \\
\hline 25. United Republic of Tanzania & 0.360 & $0.103(71)$ \\
\hline
\end{tabular}

Source: Author calculations, based on references 2 and 4 a In constant US\$ for the year 2000.

${ }^{b}$ Not applicable.

challenges (more than 57000 homicides), whereas in the Democratic Republic of the Congo, collective violence (causing about 44000 deaths) dominated the burden of violence problem in 2002.

The top four countries for DALYs lost to violence (India, China, the Russian Federation, and Brazil) also ranked in the top 10 for estimated economic value of DALYs lost to violence (ninth, fourth, fifth, and third, respectively). The fifth country in terms of estimated number of DALYs lost to violence, the Democratic Republic of the Congo, ranked 58th among WHO Member States in terms of estimated economic value of DALYs lost to violence. The United States, which ranked ninth in terms of DALYs lost with just over 1.2 million years, had the largest economic value for lost DALYs at more than US\$ 42.6 billion.
Table 3 displays 50 countries with the largest estimated economic value (in constant US\$ for the year 2000) of DALYs lost to violence in 2002 as a percentage of GDP. Countries at the top of the list include Burundi (5.1\%), Colombia $(4.3 \%)$, Liberia (3.9\%), Democratic Republic of the Congo (3.8\%), and Sudan (3.1\%). As expected, countries with large economies, such as the United States and Japan, do not appear among the countries listed in Table 3 even though the estimated economic value of DALYs lost to violence is sizeable (Table 2).

The estimated economic value (in constant US\$ for the year 2000) of DALYs lost to violence in 2002 as a percentage of GDP ranged from $0.04 \%$ to $5.1 \%$ (see Annex). Levels of confidence in the estimated values of burden of disease are based on the 2002 Global Burden of Disease Project classification scheme. With regard to cause-specific mortality, the classification scheme is as follows: Data sources and methods used for estimation of deaths by cause for each Member State are summarized into four levels of evidence. ${ }^{5}$ Additional information for estimating country-level deaths due to certain specific causes were obtained from studies, WHO technical programs, and The Joint United Nations Programme on HIV/AIDS (UNAIDS) for the following conditions: AIDS, tuberculosis, measles, pertussis, poliomyelitis, tetanus, acute lower respiratory infections, Chagas, maternal conditions, perinatal conditions, cancers, drug use disorders, rheumatoid arthritis, and war. Further details on data sources and methods for each Member State are available in WHO's Global Programme on Evidence for Health Policy Discussion Paper No. 54 (3).

\footnotetext{
5 Level 1a. Complete death registration data with cause of death coded as per International Statistical Classification of Diseases and Related Health Problems (ICD-9 or ICD-10 for 2001 and/or 2002). Less than $10 \%$ of deaths coded using ICD codes for "symptoms, signs, and ill-defined conditions," injuries from undetermined intent, cardiovascular "garbage" codes, and cancer categories for secondary or unspecified sites.

Level $1 b$. Complete death registration data available. Complete death registration data with cause of death coded using ICD-9 or ICD-10 available for an earlier time period. Less than $10 \%$ of deaths coded using ICD codes for "symptoms, signs, and ill-defined conditions," injuries where the intent is not determined, and cardiovascular and cancer "garbage" codes.

Level 2a. Death registration data available for 2001 and/or 2002. Adjustments to cause of death distribution required for incomplete registration and/or for use of non-ICD-9 or ICD-10 coding and/or for the more than $10 \%$ of deaths coded using ICD codes for ill-defined conditions, and cardiovascular, cancer, and injury "garbage" codes.

Level $2 b$. Death registration data available for latest year prior to 2001. Adjustments to cause of death distribution required for incomplete registration and/or for use of non-ICD-9 or ICD-10 coding and/or for the more than $10 \%$ of deaths coded using ICD codes for ill-defined conditions, and cardiovascular, cancer and injury "garbage" codes.

Level 3. Country information on causes of death available based on verbal autopsy methods.

Level 4. Country information on causes of death not available for most causes. Cause of death modeling used to estimate broad distribution of causes of death for Groups I, II, and III by age and sex for the country level of all-cause mortality and per capita income. Cause of death patterns within the three major cause groups based on death registration data from other countries in the region. Further country-level information and data on specific causes listed above was also used.
} 
TABLE 3. Fifty countries with largest estimated economic value ${ }^{a}$ of disability-adjusted life years (DALYs) lost to violence in 2002 as a percentage of gross domestic product (GDP)

\begin{tabular}{|c|c|c|c|c|c|}
\hline Country & $\begin{array}{l}\text { Estimated } \\
\text { economic value } \\
\text { of DALYs lost } \\
\text { (in millions } \\
\text { of US\$ } \$^{a} \text { ) }\end{array}$ & $\%$ GDP & Country & $\begin{array}{l}\text { Estimated } \\
\text { economic value } \\
\text { of DALYs lost } \\
\text { (in millions } \\
\text { of US } \$^{a} \text { ) }\end{array}$ & $\%$ GDP \\
\hline 1. Burundi & 38.2 & 5.1 & 26. Namibia & 46.2 & 1.2 \\
\hline 2. Colombia & 3748.0 & 4.3 & 27. Ukraine & 445.4 & 1.2 \\
\hline 3. Liberia & 23.3 & 3.9 & 28. Algeria & 705.5 & 1.2 \\
\hline 6. Sierra Leone & 23.8 & 2.5 & 31. Bahamas & 53.2 & 1.1 \\
\hline 7. Russian Federation & 6556.1 & 2.3 & 32. Estonia & 66.5 & 1.1 \\
\hline 8. Angola & 224.2 & 2.1 & 33. Ecuador & 178.4 & 1.0 \\
\hline 9. Congo & 71.1 & 2.0 & 34. Latvia & 91.8 & 1.0 \\
\hline 10. Bhutan & 10.6 & 2.0 & 35. United Rep of Tanzania & 102.8 & 1.0 \\
\hline 11. Côte d'Ivoire & 206.0 & 2.0 & 36. Honduras & 60.6 & 1.0 \\
\hline 17. The Former Yugoslav Rep of Macedonia & 55.7 & 1.6 & 42. Paraguay & 65.9 & 0.9 \\
\hline 18. Brazil & 9934.9 & 1.6 & 43. Kenya & 119.6 & 0.9 \\
\hline 19. Central African Rep & 14.7 & 1.5 & 44. Lao People's Democratic Rep & 17.0 & 0.9 \\
\hline 20. Guinea & 50.1 & 1.5 & 45. Philippines & 679.8 & 0.9 \\
\hline 21. Guatemala & 289.0 & 1.4 & 46. Papua New Guinea & 28.9 & 0.8 \\
\hline 22. Lithuania & 172.5 & 1.3 & 47. Senegal & 37.7 & 0.8 \\
\hline 23. Guyana & 9.6 & 1.3 & 48. Republic of Moldova & 11.9 & 0.8 \\
\hline 24. Belarus & 178.1 & 1.3 & 49. Burkina Faso & 23.0 & 0.8 \\
\hline 25. Sri Lanka & 211.5 & 1.3 & 50. Saint Vincent and the Grenadines & 2.7 & 0.8 \\
\hline
\end{tabular}

Source: Author calculations, based on references 2 and 4 .

a In constant US\$ for the year 2000.

This report attempts to provoke further discussion about the need for indepth economic analysis of the global burden of violence. The global economic values of DALYs lost to violence presented here are based on estimated DALYs. Although the WHO Global Burden of Disease Project data represent the best available at present, they too are subject to limitations and challenges, some of which may differ by country. For instance, the Global Burden of Disease Project estimates the death rate for interpersonal violence in Jamaica during 2002 was 0.5 per 100000 population. However, this is almost certainly an underestimate, as other sources report the homicide rate in Jamaica during 2002 was 39.8 per 100000 (5). Thus, the findings of this report reflect the best data available as inputs into the arithmetic equation but are nonetheless inherently imperfect.
The results of this report also reveal the challenges that arise in analyzing the burden of violence and the estimated economic values lost as a result of violence at the country level, due to variation in incidence rates, population size, income per capita, and national economy size. Countries with small economies or for which income per capita is low but where the burden of violence may be substantial may be neglected, as they do not sit at the top of a ranking list. Likewise, countries with large economies where the burden of violence may be substantial may not be visible if the focus is on economic values lost relative to GDP. It is therefore important to consider all factors, including local context, when examining the burden of violence.

It should be noted that the economic value of years lost due to disability may differ from that for years of life lost due to premature mortality. Unlike those killed as a result of a violent act, persons who are disabled as a result of violence may continue to contribute to national economies; therefore, the results in this report may overestimate the economic value of DALYs lost to violence.

Finally, in writing their report, the Commission on Macroeconomics and Health noted that by some estimates each life year should be valued at roughly three times annual earnings (1). This report does not include adjusted estimates, however, as there is no agreed-upon adjustment factor (some may argue for a multiple of two, others three, and so on).

The estimates presented in this report underscore the enormous impact of violence on households, communities, and societies. Violence is not an 
inevitable aspect of the human condition. Similar to infectious diseases and other public health threats of the past, violence can be prevented and its impact reduced using a public health approach as set forth in the World Re- port on Violence and Health (6) and its companion document Preventing violence: a guide to implementing the recommendations of the World Report on Violence and Health (7). Despite the numerous methodological challenges and data limitations, it is important to continue to try to quantify the economic burden of violence globally, particularly in low- and middleincome countries, where the burden of violence is greatest.

ANNEX. Estimated economic value ${ }^{a}$ of disability-adjusted life years (DALYs) lost to violence in 2002 as percentage of gross domestic product (GDP) for 193 WHO Member States by WHO Region (in constant US\$ for the year 2000)

\begin{tabular}{|c|c|c|c|c|c|}
\hline & $\begin{array}{l}\text { Estimated economic } \\
\text { value of DALYs lost }\end{array}$ & $\%$ GDP & & $\begin{array}{l}\text { Estimated economic } \\
\text { value of DALYs lost }\end{array}$ & $\%$ GDP \\
\hline WHO African Region & & & WHO Region of the Americas & & \\
\hline Benin $^{b}$ & 12432848 & 0.50 & Bahamas $^{c}$ & 53153569 & 1.08 \\
\hline Botswana $^{b}$ & 31598781 & 0.46 & Barbados $^{c}$ & & \\
\hline Burkina Faso ${ }^{b}$ & 23005053 & 0.80 & Belize $^{d}$ & 5305227 & 0.58 \\
\hline Cape Verde ${ }^{b}$ & 1540305 & 0.27 & Canadac & 2536731432 & 0.34 \\
\hline Central African Republic ${ }^{b}$ & 14660033 & 1.53 & Chile & 495991309 & 0.62 \\
\hline Chad $^{b}$ & 11035968 & 0.67 & Colombiac $^{c}$ & 3747997770 & 4.33 \\
\hline Comoros $^{b}$ & 1290823 & 0.59 & Costa Rica ${ }^{c}$ & 95538427 & 0.58 \\
\hline Congo ${ }^{b}$ & 71133943 & 2.03 & $\mathrm{Cuba}^{\mathrm{c}}$ & & \\
\hline Côte d'lvoire ${ }^{b}$ & 205971422 & 2.01 & Dominica $^{c}$ & 683876 & 0.27 \\
\hline Gambiab $^{b}$ & 2423708 & 0.56 & Guyanad $^{d}$ & 9611949 & 1.31 \\
\hline Ghana $^{\mathrm{b}}$ & 28719782 & 0.53 & Haitib & 12270322 & 0.33 \\
\hline Guineab $^{b}$ & 50110035 & 1.49 & Honduras $^{b}$ & 60561686 & 0.96 \\
\hline Guinea-Bissau ${ }^{b}$ & 1363670 & 0.68 & Jamaicad $^{d}$ & 5256453 & 0.06 \\
\hline Kenya $^{\mathrm{b}}$ & 119597024 & 0.90 & Mexicoc & 3487193988 & 0.60 \\
\hline Lesotho $^{b}$ & 4817822 & 0.52 & Nicaragua $^{\mathrm{C}}$ & 37932659 & 0.93 \\
\hline Liberiab $^{b}$ & 23315422 & 3.90 & Panamac & 75701714 & 0.63 \\
\hline Madagascarb & 20141652 & 0.56 & Paraguayc $^{c}$ & 65850628 & 0.91 \\
\hline Malawib & 9815630 & 0.58 & Peruc & 102254569 & 0.18 \\
\hline Malib & 21247044 & 0.75 & Saint Kitts and Nevis ${ }^{c}$ & 1649983 & 0.49 \\
\hline Mauritania ${ }^{b}$ & 8091783 & 0.72 & Saint Lucia ${ }^{c}$ & 3877267 & 0.58 \\
\hline Mauritius $^{\mathrm{c}}$ & 27026672 & 0.56 & Saint Vincent and the Grenadines ${ }^{c}$ & 2714099 & 0.80 \\
\hline Mozambique $^{b}$ & 29225707 & 0.63 & Suriname $^{d}$ & 9082600 & 0.94 \\
\hline South Africa ${ }^{c}$ & 2510749279 & 1.77 & Djiboutib & 2326307 & 0.40 \\
\hline Swaziland ${ }^{b}$ & 6406375 & 0.44 & Egypt $^{c}$ & 125236142 & 0.12 \\
\hline Togo ${ }^{b}$ & 7057155 & 0.51 & Iran (Islamic Republic of) ${ }^{d}$ & 550670283 & 0.49 \\
\hline Ugandab $^{b}$ & 113540433 & 1.72 & Iraq $^{\mathrm{b}}$ & & 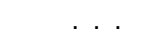 \\
\hline United Republic of Tanzaniab & 102844113 & 0.99 & Jordand & 68103161 & 0.72 \\
\hline Zambia $^{b}$ & 10409290 & 0.30 & Kuwait ${ }^{c}$ & 74735629 & 0.19 \\
\hline \multirow[t]{2}{*}{ Zimbabwe $^{\mathrm{d}}$} & 97828736 & 1.42 & Lebanon ${ }^{b}$ & 103751517 & 0.57 \\
\hline & & & & & Continues) \\
\hline
\end{tabular}


ANNEX 1. (Continued)

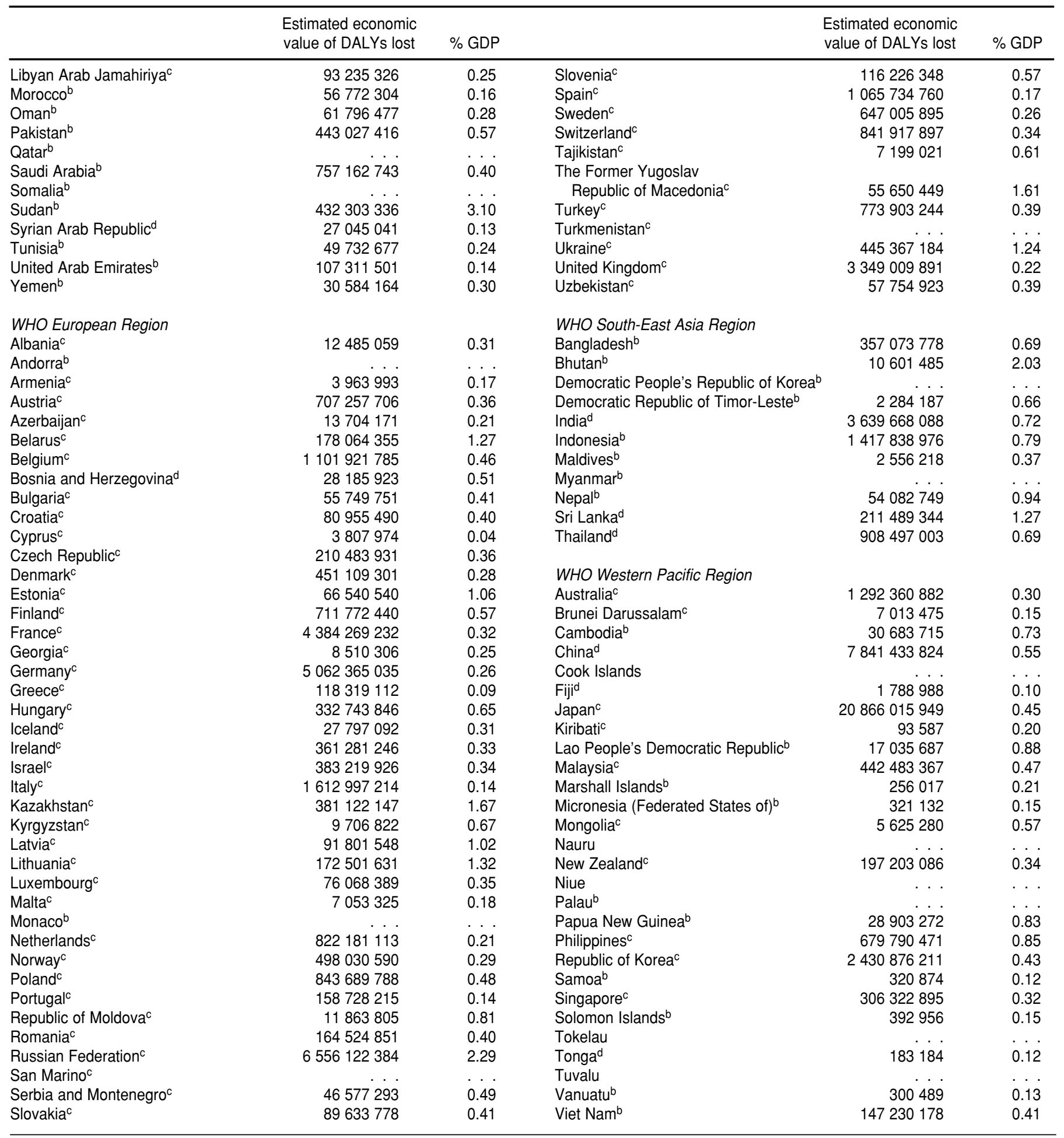

Source: Author calculations, based on references 2 and 4.

a Economic values (rounded to the nearest thousand) range from US $\$ 248000$ to US $\$ 2.51$ billion in the WHO African Region, from US $\$ 684000$ to US $\$ 42.6$ billion in the WHO Region of the Americas, from US\$2.3 million to US $\$ 757$ million in the WHO Eastern Mediterranean Region, from US $\$ 3.8$ million to US\$ 6.5 billion in the WHO European Region, from US\$ 2.3 million to US\$ 3.6 billion in the WHO South-East Asia Region, and from US\$ 94000 to US\$20.8 billion in the WHO Western Pacific Region.

${ }^{b}$ Indicates country information on level of adult mortality was unavailable and was therefore predicted from child mortality level, or cause of death information for most causes was unavailable and cause pattern was therefore predicted using cause-of-death models. Partial country-specific information on incidence or prevalence of non-fatal causes was available.

${ }^{c}$ Indicates death registration data (complete or incomplete) containing useable information on causes of death was available for the country and was used to adjust regional YLD (years lost due to disability) distributions for causes with significant case fatality. Partial country-specific information on incidence or prevalence of non-fatal causes was available.

${ }^{d}$ Indicates other forms of information on child and adult mortality or causes of death (e.g., verbal autopsy) were available; country-specific information on mortality for specific causes was available; and partial country-specific information on incidence or prevalence of non-fatal causes was available. 


\section{REFERENCES}

1. Commission on Macroeconomics and Health. Report of the Commission on Macroeconomics and Health: macroeconomics and health: investing in health for economic development. Geneva: World Health Organization; 2001.

2. World Health Organization. Global Burden of Disease (GBD) 2002 estimates: incidence, prevalence, mortality, YLL, YLD and DALYs by sex, cause and region, estimates for 2002 as reported in the World Health Reports 2003 and 2004 [Internet site]. Available from: http:// www.who.int/healthinfo/bodgbd2002/en/ index.html. Accessed 10 May 2007.

3. Mathers CD, Bernard C, Iburg KM, Inoue M, Ma Fat D, Shibuya K, et al. Global Burden of Disease in 2002: data sources, methods and results. Global Programme on Evidence for
Health Policy Discussion Paper No. 54. Geneva: World Health Organization; 2003. Available from: http://www.who.int/healthinfo/paper 54.pdf. Accessed 10 October 2007.

4. World Bank. World Development Indicators Dataset [Internet site]. Available from: http://ddp-ext.worldbank.org/ext/DDPQQ/ member.do? method=getMembers\&userid $=$ $1 \& q u e r y I d=135$. Accessed 10 May 2007.

5. Lemard G, Hemenway D. Violence in Jamaica: an analysis of homicides 1998-2002. Inj Prev. 2006;12(1):15-8.

6. World Health Organization. World report on violence and health. Geneva: WHO; 2002. Available at: http://www.who.int/violence_injury_ prevention/violence/world_report/en/.
7. World Health Organization. Preventing violence: a guide to implementing the recommendations of the World Report on Violence and Health. Geneva: WHO; 2004.

Manuscript received on 24 October 2007. Revised version accepted for publication on 16 April 2008.
RESUMEN

\section{Valor económico de los años de vida ajustados por discapacidad perdidos por la violencia: cálculos para los Estados Miembros de la OMS}

La violencia es un importante reto para la salud pública y conlleva considerables consecuencias económicas para las personas afectadas, sus familias y la comunidad. A partir de datos de la Organización Mundial de la Salud (OMS) y del Banco Mundial se estimó el valor económico de los años de vida ajustados por discapacidad (AVAD) perdidos en 2002 por la violencia. Los datos de los Estados Miembros de la OMS se presentan como porcentajes de su producto interno bruto (PIB). Según los resultados, se perdieron 48,4 millones de AVAD como resultado de 1,6 millones de muertes por violencia en el año 2002, para un valor económico total estimado de US\$151 000 millones (en dólares estadounidenses de 2002). El valor económico de los AVAD perdidos por la violencia en los 193 Estados Miembros de la OMS varió de 0,04\% a 5,1\% de su PIB. Se debe hacer un mayor esfuerzo en la cuantificación de la carga económica de la violencia en el mundo, particularmente en los países de ingresos bajos y medios, donde la carga de la violencia alcanza los mayores valores.

Palabras clave Violencia, costo de enfermedad. 